\title{
EDITORIAL
}

\section{Art approaching science and religion}

\section{T} he articles presented in this issue of Approaching Religion originate from an interdisciplinary symposium conducted under the title Art Approaching Science and Religion. In May 2016 this explorative and engaging symposium gathered researchers and artists from the Nordic countries, Europe and North America to Turku ( $\AA$ bo), Finland, for three days of lively discussions and sincere scholarly debate, together with artistic interventions. The fruits of these presentations and conversations have now been edited for this publication, in which scholars from such varied fields as religion, philosophy, technology and economics engage in dialogue with architects, painters, dancers, and textile artists on the fundamental questions that arise from a triangulation of the fields of art, religion and science.

HOW CAN SCIENCE AND RELIGION be explored from the perspective of the arts? This central question from the symposium has also formed a point of departure for the different contributions to this volume. The texts represent different approaches to how aesthetics, as a wide spectrum of historical and contemporary traditions, is formed together with strands of artist research, art criticism and art history as well as the humanities, philosophy, religious studies, technology and economics. The symposium was funded by Åbo Akademi University, the Amos Anderson Laboratory for Artful Thinking, the Donner Institute for research in religious and cultural history, the Kone Foundation, and the Allan and Bo Hjelt Art Foundation. However, the most important prerequisite was of course the number of contributors, who accepted the invitation and call to make presentations.
If you bring art, science and religion together in a common discussion, you need to cope with an extraordinarily complex constellation of human practices, including a history often associated with conflicting claims, violent attacks, and ironic misconceptions. From a historical point of view, art, science, and religion have a long, shared history of mutual involvement and influence. Yet the history of their internal relationships is also full of complications, not least in modernity. We only need to remind ourselves of the fact that the autonomy of artists and scientists, often taken for granted today, has actually been possible to achieve only as the result of a long struggle for independence from religious authorities. The grand narrative of this process is the story of secularization. According to the standard version of this story, we should not expect any insights at all from religion and art. Science was supposed to replace religion - and, in a best-case scenario, also art. Human civilization was considered to move from mythos to logos - with the disenchantment of the world as a final result!

Over time, this narrative has broken down. Yes, the times they are really a-changing and today, in our post-secular age, things have turned out to be much more complicated. Thus, a religious person can no longer automatically be recognized as a not yet fully modern person. There seems to be no necessary link between modernization and secularization. This does not mean, however, that we can turn back to a pre-critical stage and join the chorus of 'give me that old time religion', because the secularization process is in no way to be considered as something which has been left behind - secularization continues on.

At the same time, an increasing number of people seem to realize that secularization itself can be con- 
sidered to be a religious phenomenon: an invention of theology itself. It becomes obvious to anyone participating in an academic celebration that our traditional institutions of knowledge are grounded in a religious prehistory - the university has emerged from the shadows of the cathedral. The history of science and the history of religion are intertwined - and both are dependent on art and artful thinking. Today, we can thus no longer hide from the fact that there is much more art and poetry in both science and religion than we had earlier presumed. Epistemologies are formed by traditions which are embedded in culture and society. Science is in a constant need of models, metaphors and narratives for its investigations - and underneath the world of facts and concepts, we approach a web of symbolic systems, living and dead metaphors. Religion without art is dead. More fundamental than any doctrine are the symbolic systems of religions. From this we understand, that art, science and religion are in reality much more intertwined phenomena than previously expected.

As for the disposition of this issue, it opens with a reflection on the commonalities and inconsistencies between scholarly and artistic approaches, delivered as an opening speech at the symposium by the Chancellor of Åbo Akademi University, Ulrika WolfKnuts. 'Creativity, freedom and order are the characteristics of play, and all of them can be found in both art, scholarship and science, she concludes. The opening address also includes two eloquent sonnets written by Professor Emeritus Erik Andersson, directly inspired by the symposium theme and performed in a preliminary form during the event. Thus, they contribute to the conversations taking place among the participating scholars. The article section opens with four texts by researchers invited as keynote lecturers to the event. Mark C. Taylor reflects on the aesthetic turn in philosophy while Melissa Raphael provides insights into the creation of beauty and its destruction within contemporary Jewish art, followed by a response from Ruth Illman. Serafim Seppälä discusses the aesthetics of commemoration in his article dealing with a genocide memorial in Yerevan, Armenia, followed by a response from Catharina Raudvere. Finally, Ken Bloomer engages with cosmic aspects of ornaments from the point of view of architecture.

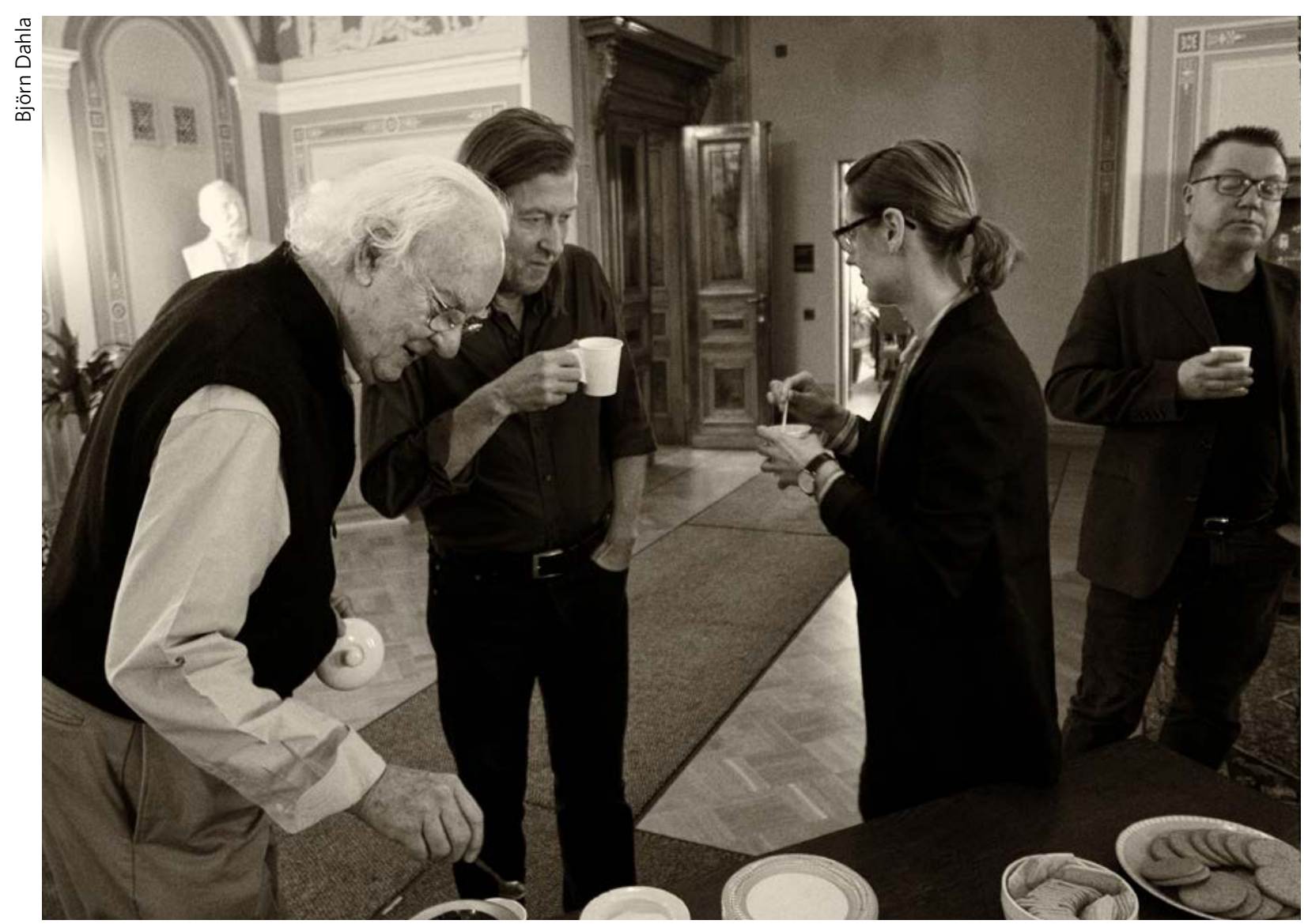

The symposium participants (from left) Kent Bloomer, Jan-Erik Andersson, Sarah-Allegra Shönberger and Bengt Kristersson Uggla during a coffee break. 
These presentations are followed by four articles where the point of departure is taken from the study of religion and theology, regarding and relating to the arts and sciences from this platform. In her contribution, Laura Hellsten analyses the theology of dance while W. Alan Smith illuminates the mystical trajectories found in Salvador Dalís art. Ali Qadir and Tatiana Tiaynen-Qadir, for their part, bring Islamic and Orthodox art together with perspectives on interreligious dialogue, while Maija Butters presents an ethnographical study of the role of aesthetics for terminally ill people.

The subsequent set of articles approaches the theme from another vantage point; that is to say beginning from within the arts. These articles are presented by researchers of art and technology as well as practising artists. Sarah-Allegra Schönberger contributes with perspectives on Hindu and Buddhist aesthetics by discussing the iconographic transformation of the pan-Asian divinity Vaiśravana. Sari Kuuva, on her part, approaches the complex idea of evolution in works by the artists Edvard Munch and Damien Hirst. The visual artist Denice Ziegler's article is based in art research, documenting an artistic intervention in urban space, while Birgitta Nordström takes her point of departure from within textile art as she discusses existential dimensions of funeral textiles. Lastly, Henrik Åhman returns to Taylor's discussion of the aesthetic turn, relating it to contemporary technological advancements.

Finally, the issue contains a section of review articles and reflections arising in the aftermath of the symposium, considering the theme from a more general, reflective point of view. Jan-Kenneth Weckman discusses the art exhibition Ornament \& Beauty, arranged in parallel with the academic seminar at Titanik Gallery in Turku, and Malin Fredriksson presents a review of relevant new literature in the field.

In times when we have to re-think - and re-invent - the university, it is absolutely necessary for science to take art seriously into consideration, to involve and collaborate with artists, but also to rediscover the artful and artistic aspects of research and education as well as religion and faith. Yet still today the interplay between art, science and religion takes us into dangerous cognitive battlefields. In this situation, it is an important challenge to transform violent battles of interpretation into productive conflicts. By putting art in the driving seat and approaching science and religion from the perspective of the arts, we have reversed the traditional roles. To many, this may seem controversial. If someone were to consider the theme of this symposium - 'how can science and religion be explored from the perspective of the arts?' - to be a provocation, they would be absolutely right. It is time for art to approach science and religion. You are welcome to join us in this enterprise!

\section{Ruth IIIman and Bengt Kristensson Uggla \\ Editors}

Ruth Illman is docent of comparative religion at Åbo Akademi University and director of the Donner Institute for Research in Religious and Cultural History in Turku, Finland. Her main research interests

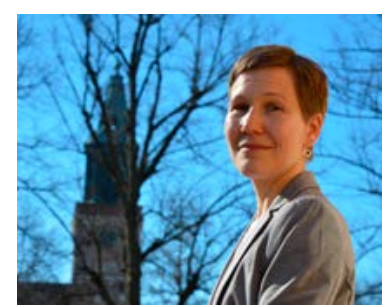
include interreligious dialogue, religion and art, and contemporary Judaism. Among her recent publications are the books Art and Belief: Artists Engaged in Interreligious Dialogue (Routledge 2012) and Theology and the Arts: Engaging Faith, co-authored with W. Alan Smith (Routledge 2013, paperback edn 2016). She is the editor of Approaching Religion and Scripta Instituti Donneriani, published by the Donner Institute, and, together with Karin Hedner Zetterholm, of the peer-reviewed journal Nordisk judaistik Scandinavian Jewish Studies.

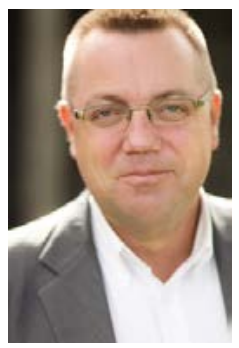

Bengt Kristensson Uggla is Amos Anderson Professor of Philosophy, Culture, and Management at Åbo Akademi University. After defending his doctoral thesis on Paul Ricoeur at Lund University (Sweden) in 1994, he has been associated with a number of European and American universities, together with significant management positions, such as Dean at the IFL, Swedish Institute of Management: StockholmBrussels-Moscow 2001-4. He is a member of the board editorial committee of the Tomonobu Imamichi Institute for Eco-Ethica (Tokyo-Copenhagen), member of the European Cultural Parliament (ECP), he was head of the Nomadic University for Art, Philosophy and Enterprise in Europe 2006-10 and is now acting as the scientific leader of the Amos Anderson Laboratory for Artful Making, AmosLAB. Kristensson Uggla has developed a kind of cross-disciplinary hermeneutics in a number of books and articles; the following books are still available in English: Ricoeur, Hermeneutics, and Globalization (2010), Trust and Organizations: Confidence across Borders (2013), and Becoming Human Again: The Theological Life of Gustaf Wingren (2016). 